\title{
Contemporary Challenges to Personnel Development in the Industrial Company
}

Fahri Idriz*, Marin Geshkov*

\begin{abstract}
For every business which wants to grow and develop, the first and most important rule is to invest in human resources. The most important investment a business can make is to educate its human resources. In many sectors, human labor is and will remain irreplaceable. One of the most substantial aspects of business growth is competitive power. This competitive power is discovered, used and acknowledged by the management. Managers use the potential of skilled workers to increase their business' production directly or indirectly while motivating them to reach a climax in their professional development. Every industry, thanks to its successful managers and marketers, can offer high-quality products and services. Human resources are the main component of a successful business. However, there are some contemporary challenges in front of personnel development. Our study looks for these challenges, analyses them and proposes some measures to effectively manage personnel development.

Our paper is organized into the following main sections: Introduction- familiarizing the readers with the main issues in $\mathrm{HR}$, Research Goals - discussing main research goals in the paper, Research Methods - using observational
\end{abstract}

and analytical methods, Results- discussing main results and applications, and Conclusion.

Keywords: business, purpose, human, growth, success.

JEL: J24, J53, J62

\section{Introduction}

Uuman resources are the most Iimportant asset of a business organization, essential to ensure the growth of the organization thanks to the competitive advantages that they possess. These competitive advantages are discovered, used and built by the management. Managers use the potential of employees in the labor process to add directly or indirectly more value to the enterprise's production, motivating people, aware of the fact that everyone wants to get to the top of their development. Therefore, the leader-manager of every organization should inspire with personal examples and indomitable spirit the personnel to look ahead, to be proactive and to go beyond their immediate interests. People must believe in inspiring growth ideologies.

Every industry can offer high-quality products and services thanks to successful managers and marketers. Management is a constant lookout is for balance: between resources and wealth, income and expenditure,

* Fahri Idriz is a Ph. D, a chief assistant at the Technical University, Sofia, College Sliven.

${ }^{* *}$ Marin Geshkov is a Ph. D, a chief assistant in the Department of Industrial Business of UNWE. 


\section{Articles}

human factor and automation, projects and processes, status quo and innovation. Consciously or not, it obeys the natural law of actions physically aligned (Drucker, 2003).

As a result of man's purposefulness to achieve sustainable business development, competitiveness, transition to higher evolutionary levels, managing economic processes is a basis for business growth. In its very center are people managed by people with their human desires, actions and abilities, management and personnel determining the well-being of mankind (Drucker, 2005; lliev, 2005).

Man performs different roles in economic life due to differences in mental activity, needs, knowledge, skills, abilities, and potential for evolvement. Man detects, masters, accumulates and manages existing opportunities, uses them to create goods and services that meet physiological, mental and other needs. At the same time, man seeks the potential to evolve, improve, refresh, modernize and refine existing abilities. The collective image of human activities is that of an engine of human progress. Man possesses qualities that enable him to play a major role in business development. Here are some examples (lliev, 2016):

- Man is a generator of ideas; possesses qualities such as imagination, creativity, intuition, insightful mind that help him create a complete business service or design individual services.

- A man invests in ideas; to do so, he/she acquires assets, knowledge, skills, and risk assessment competencies to successfully redistribute and reinvest in a way that ensures maximum future return.

- As a leading manager, man organizes, motivates, and coordinates projects or work units, optimizing the use of resources, maximizing profits and enhancing business development with a team of people committed to business success throughout good times or crises (Sharma, 1999).

- As a back-office employee, man has technical skills, technological knowledge is open to innovation and ready to continuous training, challenged by the pace of constantly evolving market.

- As a front-office employee, man is communicative, customer-friendly, combinative, self-organized and disciplined, and these attributes help him to keep loyal customers, attract potential clients and build a confidence service organization.

Being proactive, voluntarily agreeing to perform tasks, dedicated, and ready to take on more responsibilities - that makes a man most valued for key positions in each organization (lliev 2016).

\section{Development of human resources in the industrial firm}

Human resources development is a complex process that uniquely combines individual and organizational activities whose results bring benefits to both individuals and businesses. To invest in human resources development is to invest in the potential of your organization to become more competitive and successful on the market.

Seeking to enrich knowledge and skills in order to have a workforce that has more capacity to offer the domestic and the external labor market is of a key importance for the firm as well as for those employed and is a factor to gain or maintain a job in a field where interaction between personal characteristics and labor market" is emphasized.

For a person to master the most effective business processes, he/she must know the critical success factors in business process management, the necessary balance between business environment and business processes, between assigned tasks 


\section{Articles}

and information systems. Reasons to seek and pursue the development of business processes could be various:

- infrastructural improvement;

- rehabilitation and reconstruction;

- complete replacement of obsolete (physical and moral) technologies with new ones;

- complying with time parameters: if someone can offer a service faster and timelier than you, you will be replaced.

Every task should be treated as a priority, executed quickly and qualitatively. In this way, people (partners, contractors and all users of your services) will speak well about you and your business. The best advertising in business is word-of-mouth, to speak in a positive way about your products and services. Train your people and yourself to act quickly and the best way when people want or need you (Sharma, 1999).

Given that the sustainable competitive advantage is based on business-specific knowledge that cannot be found and acquired easily on the labor market in a ready-to-use form (human capital), it is concluded that the availability of human capital is of fundamental importance for the well-being of the firm.

Bulgarian business practices and especially industry need to increase the relative share of employees who meet the requirements to be defined as human capital and human resources management mechanisms on the scientific basis are a significant prerequisite for validating success policy.

The need for the development of human resources in the respective company is indisputable. A major part of HR development is related to employee motivation. There are three major motivation theories: two-factor theory, work-adjustment theory, and goalsetting theory.

Two-factor theory. The two-factor theory is developed by Frederick Herzberg. According
Contemporary Challenges to Personnel Development

in the Industrial Company

to him, there are two major groups of factors that are important for employee motivation. The first set of factors is called motivators. Those are internal job factors that lead to job satisfaction and higher motivation. In the absence of motivators, the employees most likely will not be motivated up to their maximum and will not perform expectedly. Some examples of motivators are work itself, achievement, recognition, responsibility, and opportunities for advancement. The second set of factors is called maintenance or hygiene factors. The absence of those factors would lead to active dissatisfaction and demotivation among the workers, and in some cases to avoidance of the work altogether. Among some of the hygiene factors, we could mention company policies, working conditions, job security, salary, employee benefits, relationship with supervisors and managers, etc. According to Herzberg, if management provides the appropriate hygiene factors, an employee will not be dissatisfied with their jobs, but neither will they be motivated to perform at their full potential (Mejia, Blakin, Cardy, 2011).

Work-adjustment theory. According to the work-adjustment theory, every worker has unique needs and abilities. Work adjustment theory suggests the employees' motivation levels and job satisfaction depend on the fit between their needs and abilities and the characteristics of the job and the organization. A poor fit between individual characteristics and the work environment may lead to reduced levels of motivation. According to the workadjustment theory, to successfully motivate the employee, a job design must correspond to employee's needs as well as an employee must have a greater part in the decisionmaking process (Mejia, Blakin, Cardy, 2011).

Goal-setting theory. A goal-setting theory, developed by Edwin Locke, suggests that employees' goals help to explain motivation and job performance. That means that 


\section{Articles}

goals set by an employer could motivate the employee if those goals are set in a particular way. According to goal-setting theory, motivating goals must be clear and specific. Employees will be more motivated to accomplish difficult rather than easy goals. In many cases, goals that require active participation by an employee in the decisionmaking process are much more motivating than goals and tasks simply set by the manager. And finally, employees who receive frequent feedback on their progress toward reaching their goals sustain higher levels of motivation and performance that employees who receive sporadic or no feedback (Mejia, Blakin, Cardy, 2011).

\section{Specifics in Human Resource Management in the Industrial Firm}

Governance arises and evolves as a need for concerted actions to get the expected outcome of a particular person's activity the activity of the leader-manager. He/she manages human resources, which means he/ she sells its services and products, encourages them to seek effective transaction termination and long-term customer retention. On the other hand, he/she constantly motivates and inspires excellence. The manager is the person who sets goals, plans, organizes, manages, and controls human, financial, material and information resources. $\mathrm{He} / \mathrm{she}$ :

- selects activities to be carried out;

- outlines results to be expected;

- determines the timeframe for achieving the goals;

- defines costs;

- selects criteria to confirm that the goal has been achieved;

Management is related to people's motivation, choice of method and choice of style. The leader-manager makes different decisions about what needs to be done, how and by whom, and for what time. $\mathrm{He} /$ she organizes respective elements of the organization in time. and space, preserving the organizational equilibrium and defining objective criteria for measurement, assessment, and comparison.

Drucker (2009) identifies the knowledge, energy, and loyalty of company employees as their most important asset in the modern economy. According to him, the skills of employees may be in different areas, but it is good that they develop in a direction consistent with their interests. On their success, commitment, motivation, and teamwork depend the success of each organization.

The scientific argument that human resources are (can be) a cutting-edge and sustainable competitive advantage for organizations find evidence in business practice. Established and developed competences of human resources, their increased labor motivation, ultimately result in the growth of the organizations. Employees developed in human capital can be defined as the "engine" of business growth.

Achieving a competitive advantage of human resources and hence business growth is undoubtedly a complex challenge, it can be a successful mastering through adequate policy and management mechanisms of organizations on the one hand and personal responsibility and organization of each member of the organization, on another.

Mejia, Blakin, Cardy, (2011), find a relationship between the degree of proficiency of personnel and the profitability of the company. According to their study training and development of personnel is a key factor for the company's success.

\section{Career development of personnel in the industrial firm}

Career development of personnel can be done in many different ways in 


\section{Articles}

modern organizations. In a large number of companies, the responsibility for the career development of personnel is borne by the employees themselves. Career development of personnel depends to a large extent on the type of organization. In modern organizations with a bureaucratic structure and many levels of governance, greater opportunities for personnel growth are created, unlike organizations with two levels of government. On the other hand, an excessive careerist approach by employees is also not desirable to be tolerated by management. It is extremely important to establish a balance between the employees' career ambitions and the needs of the organization. Creating a career development plan for personnel almost always consists of three phases: evaluation phase, referral phase and development phase (Mejia, Blakin, Cardy, 2011).

\subsection{Assessment phase}

The career development assessment of personnel includes activities ranging from individual assessment to evaluation based on criteria provided by the organization. The goal of the evaluation, whether conducted by the organization or by the employee himself, is to identify the strengths and weaknesses of the employee. During the assessment phase, the following parameters are established:

- a career path for the employee that is realistic, achievable and responsive to both the employee's ambitions and the organization's needs.

- weaknesses that the employee has to overcome in the path of his growth (Mejia, Blakin, Cardy, 2011).

\subsubsection{Self-assessment phase}

The self-assessment phase is of utmost importance for organizations that want to create opportunities for career development for their employees. The main tools used in the self-assessment phase are collections
Contemporary Challenges to Personnel Development

in the Industrial Company

of test exercises and seminars. Testing exercises often include materials related to specific approaches to career development in the organization, as well as descriptions of various career paths and opportunities within the organization. Career development seminars, on the other hand, can be conducted either by HR representatives in the organization or by external lecturers such as consultants, lecturers from a local university, etc. Employee participation in these seminars is desirable because at these seminars employees gain the most complete picture of their career development opportunities (Mejia, Blakin, Cardy, 2011).

No matter whether in the individual assessment phase collections of test exercises or seminars are used, the three main exercises covered are exercises for assessing the employee's level of skills, exercises to identify the employee's core interests, and exercises to establish the values of the employee.

- Exercises to identify employee skill levels most often require employees to make a shortlist of their achievements. Once employees have drawn up their list of achievements, they have to identify the skills used to achieve these achievements.

- Exercises to identify employee's core interests are necessary to reveal his or her fundamental interests. According to the point of view of human resources management, the aim is to establish whether there is a match between the employee's main interests and the interests of the organization as a whole. For the career development of the employee is important to identify related interests between the employee and the organization.

- Exercises to establish employee's values most often include employee sorting individual values by importance. Such an exercise would require the employee to prioritize certain values such as security, 


\section{Articles}

power, income, family, etc. Knowing the priority of their values well, employees would make better decisions about their career development (Mejia, Blakin, Cardy, 2011).

\subsubsection{Organizational assessment phase}

The next step in the career development of personnel is the organizational assessment phase. To this end, the organization may use the so-called testing and assessment centers for personnel, and the application of these centers is particularly relevant to the selection and evaluation of managerial positions. The core managerial qualities that are valued by the organization are managerial skills, problem-solving skills, and team-building skills. Different types of research show that these testing centers have a positive impact on managers for months after exercise. Some organizations are also conducting so-called psychological tests to help employees better understand and realize their strengths and weaknesses (Mejia, Blakin, Cardy, 2011).

Personnel evaluation is the next phase of personnel assessment by the organization. In the case of personnel career development, so-called future-stage attestations should be used to provide employees with important information about their strengths and weaknesses, as well as possible career paths ahead of them.

Promotability forecasts is a technique used by managers that allows them to identify which of their employees have the potential for promotion. Employees with potential for promotion are given opportunities to help them achieve their career goals (Mejia, Blakin, Cardy, 2011).

Succession planning is a technique used in career development for personnel to prepare people to fill managerial positions. The organization identifies those employees who have managerial potential. At a later stage, potential employees are examined by using their competency ratings for the position. Planning an alternate/deputy manager is particularly necessary when the company needs management personnel but does not need it to be recruited from outside and interrupt the production process. Succession planning is also of particular importance for small companies where the owner is traditionally also the company manager. The lack of a planned alternate in small companies leads to problems and eventual interruption of the production process in case the company owner has to temporarily or permanently leave his / her post due to travel, illness, retirement, etc. (Mejia, Blakin, Cardy, 2011).

\subsubsection{Orientation phase}

The career orientation phase determines the type of career employees follow and the steps they need to take to realize their career goals. Determining the right direction in career development requires a correct understanding of the current position and possible career paths. It is extremely important that career development paths should have employee's current position as a starting point for the career development to be realistic and achievable.

One of the main models used to guide career development is the competency model. Based on this model, the employee, as well as the organization, can identify the competencies an employee should possess to occupy a higher position and pursue career growth (Mejia, Blakin, Cardy, 2011). Giving the right direction to the career development of personnel is a complex task, in which several activities such as personnel recruitment and selection, personnel assessment and personnel training, should be involved.

Directing the personnel to their proper career development can take place in different ways, such as individual consultations with $\mathrm{HR}$ representatives or through information 


\section{Articles}

services. In individual consultations with representatives of the Human Resources Department, the employee receives the most complete information about possible directions in his / her career development. Information services, on the other hand, represent several services that inform the employee about possible open positions in the organization, for which the employee could apply (Mejia, Blakin, Cardy, 2011).

\subsubsection{Development phase}

The development phase includes actions that create and empower employees with the skills required to take up and validate a job, and the manager's active participation in this phase together with the employee is of importance. The manager of an employee can act as a mentor - to show the employee how to approach a particular task, what further skills he/she can develop to take the desired higher position, etc. The development phase is particularly important when the skills necessary to occupy a higher position need to be identified and acquired. In many organizations, the mentor may not be the manager of a particular employee, but a higher-level employee who helps the employee with valuable job counseling. The development phase can also include spontaneous meetings between employees and their supervisor, in which employees can learn about prospects for future growth, possible open positions, etc. Some organizations also include financial support programs for those employees who enroll at university to acquire a higher degree required by the organization (Mejia, Blakin, Cardy, 2011).

\section{Impact of the economic crisis on the personnel career development}

An economic crisis can influence various aspects of the economy of an industrial company, including the career development of personnel.
Contemporary Challenges to Personnel Development

in the Industrial Company

At the end of 2007 and early 2008, the US economy experienced signs of economic stagnation. Unemployment rates were rising and the gross domestic product was in decline. Despite the efforts of the US government to stabilize the economy, problems deepened (Tridico, 2011). In October 2008 came the collapse of US money markets, followed by complete chaos on real estate markets. As a result, many Americans lost their homes because of their inability to meet monthly mortgage payments. Begun as a financial and mortgage crisis, the crisis gradually covered all sectors of the US economy and led to severe reduction in the gross domestic product and the incomes of the population and to unrecognized levels of unemployment - up to $11 \%$, compared to the typical for the economy $3-4 \%$ (Claessens, Tong, Wei, 2011). By the end of 2008 , the USA was already talking about a national crisis the size of the Great Depression of 1930 . In early 2009 , the US economic crisis left the country and gradually affected much of the world, including and EU countries. In the middle of 2009 , the crisis turned into a global economic crisis. It did not bypass Bulgaria. Its manifestations were felt strongly after years of economic growth and by the end of 2009, a decrease in consumption has been observed, leading to serious contraction of the manufacturing sector and an alarming increase of unemployment. Despite efforts to achieve financial discipline and stability on the part of the government, the country continued to experience the effects of the global economic crisis. The global economic crisis also affected human resources in industrial firms, posing many challenges, analyzed below.

In the face of an economic crisis, organizations face huge challenges in terms of constantly falling sales, reducing the revenue of the organization, lowering personnel salaries and lowering personnel 


\section{Articles}

numbers. The economic crisis challenges both the organization and its employees.

To analyze the impact of the economic crisis on the career development of personnel, we must take into account the fact that employees' career growth is influenced by two sets of factors, namely individual and organizational. In other words, a career growth needs not only certain skills and knowledge on the side of the employee but also higher-level positions opened in the organization for which he/she can apply. Last but not least, there should be an ambition for career growth among employees, a constant incentive to look for higher positions. Often, for a successful career, the employee has to change several organizations.

The mobility of the workforce is one of the reasons for the successful realization of the employees. If an economic crisis harms employees' career development due to the closing down of certain positions and personnel shortages on one hand, on the other hand, the economic crisis could have a positive effect on their career growth. For example, an employee made redundant by an organization becomes more mobile and is likely to seek work in another organization that offers higher opportunities for personnel development. The high mobility of the workforce during an economic crisis also leads to vacancies in higher positions in the organization, in which the employee works. Thus the employee can apply for a higher position within the organization itself and achieve career advancement. Therefore, in some cases, the economic crisis can have a positive effect on the career growth of employees, making them more ambitious, more demanding and proactive in finding better career prospects. Restructuring firms in the context of an economic crisis can also lead to job creation and the emergence of new opportunities for career growth. This gives us reason to assert that the effect of the economic crisis on the career development of personnel should be interpreted in two ways, analyzing both its negative and its positive aspects.

\section{Leadership approach to personnel development in the industrial company}

Leadership is a process in which a person influences the behavior of a particular group to achieve the goals of the group or organization. Different leaders use different leadership styles to motivate employees to achieve these goals. The leaders stand out in the organization; they always attract attention because their influence on the effectiveness of each organization is most significant. Leadership that stems from leaders' ability to build a vision, gather followers and unlock and direct their energy into achieving that vision is essential for the organization.

Human resources management is a function of managing people in an organization. In the 1950s it is called Personnel Management, and the reason for it is the need for qualified personnel with skills and experience. Leaders start investing in personnel training, and payment-matching-achievement systems are defined (Carnegie, 2013). Interest in leadership is traditionally high, but with varying intensity over time. Effectiveness of leadership is an issue directly related to the one about its nature and is fundamental to the entire leadership concept and social practice. On leaders' vision and their actions depends the dynamics of every society. The role of leadership for the progress of society varies with historical and social processes. Leadership is a constant phenomenon that follows the evolution of man, technology, society and nature (Carnegie, 2009).

A leader is an active person. He/she does not necessarily have to be a leader 


\section{Articles}

in the hierarchy. The leader is aware of the challenges a situation provides and responds by adapting the group's actions to solving tasks and achieving goals. Each leader must have a clearly defined goal and direction of the actions taken, together with a clear sense of opportunity (Sharma, 2015).

\section{Impact of the leader on personnel development in the industrial company}

In each group, there is a leader. He/she may be appointed officially or might be an informal leader due to his/her knowledge, skills and organizational abilities. The manager is appointed from outside and the leader rises "from below". A leader can only become a person, who can lead the group to success, conquering new heights while uniting the team by building new values. In successful organizations with long-term, sustainable success, leaders in senior management work on forming leaders at all levels of the organization. The effective leader has not only qualities and skills but is capable of preparing qualified followers and successors as well. This is considered to be one of the main functions of senior executives and is carried out whenever possible. This is part of the corporate culture of the organization, for which mentoring and training are the engine of development. (Iliev, 2016; lliev, 2005).

Effective leaders have a "transmitting point of view" - clearly structured system of ideas, knowledge, and values that leaders outline in a way, which does not impede the perception of their followers. Leaders are like mirrors of the group - they appear in it reflecting its specifics and realize themselves within (with values, mission, expectations, and intentions). With organizational skills they can quickly and properly assess the situation, formulate priorities, distinguishing feasible from impractical precisely enough to determine the
Contemporary Challenges to Personnel Development in the Industrial Company

way of solving tasks. Anyone apt to create an idea and inspire the team to realize it most certainly will be seen as a leader. Some personal qualities such as charisma can help with leadership, but leadership is not entirely based on that. The management techniques that can be learned are much more important (Sharma, 2013).

The leader likes to take risks and is not afraid of failure. The leader, unlike the manager, constantly forces his teams to do new and new things. Many countries around the world do not have rich deposits, underground wealth, but they have their leaders who lead their organizations to world success thanks to their insight that people are the greatest treasure in any organization. The manager is monotonous and the leader is forward-looking. The leader is the one who discovers revolutionary ideas of personal and organizational improvement. The lack of efficiency in most business organizations arises from obsolete thinking and inefficient management systems that work simply by habit. That is why the leader always puts people first to obtain the best results from their skills and knowledge. (lliev, 2016; Iliev 2005).

\section{Role of an effective leader in human resources development}

The overall qualities of the leader, encompassing his/her attitude towards the world and people, his or her skills and competencies define the notion of leadership effectiveness. Without diminishing the importance of other determinants (permanent and variable) of leadership, priority is given to the so-called personal factor. A prerequisite for effective leadership is credibility, and credibility is gained while the real effectiveness of leadership is linked to the ability to intervene in a difficult social situation, change it, and make change remarkable. The term 


\section{Articles}

"leadership efficiency" focuses primarily on the consequences, the results of an effective style of leadership behavior and impact, skills to communicate with people, to manage and control the processes in the organization as a whole. The effectiveness of leadership behavior is assessed based on personal characteristics, through which the leader achieves good results regardless of the circumstances and situations. The emphasis is on the leadership power to convince and unite people in pursuing defined goals. This is also the most important criterion in assessing the leader's potential. What methods or a combination of methods would be used is entirely a personal choice of the leader (lliev, 2016).

Leadership is characterized as a twoway process - guiding and following. It is a major category in social psychology, which deals with interpersonal relationships of leaders among people. The normal course of leadership is the leader to win the trust of his followers. Otherwise, the chain of the twosided process of leading - following is broken. Effective leadership implies a purposeful, steady and persistent activity of leaders and followers to achieve community goals. Leadership is a process whose results can be objectively assessed only after a certain time - in the indefinite future. The leadership efficiency is far more complex than a sum of some results and it is difficult to be defined with clarity (lliev, 2016).

Leadership is a practice of specific behavior and the use of certain qualities to cope with change or seeking change. Nothing in life is constant and no leader can lead an organization if he/she cannot evolve.

Leadership is governance, but also something else that is more important. It is more inspiration and serving the common interest by setting new standards, taking risks, vision, and action for the future. Leadership is a creative activity and the evaluation of its effectiveness cannot be done only based on rational criteria (lliev, 2005).

Unlike the manager, the leader does not follow job descriptions; he/she combines humanity with courage in the process of management. Fear and respect are fundamentally different emotions. The leader does not neglect the interests of his people; he/she helps them realize their dreams. The leader is part of the team, a people's person. People want a leader to respect and be respected by him/her; they want someone with a glimpse, even a fleeting one, of a cause worthy of their aspirations, so that their mundane work makes sense. (Sharma, 2013).

\section{Conclusion}

Nowadays, the development of personnel in the industrial company is faced with many challenges. The global economic crisis is a serious test for the stability of the industrial company. Negative aspects such as rising resource costs, shrinking market, and fierce competition are just some of the challenges facing the business. Years of economic crisis pose serious challenges to the career development of personnel. And while in the pre-crisis period the employee has defined certain career paths, in an economic crisis the employee's career future is too vague. The economic crisis leads to job closures and job cuts, but it also leads to dynamism both in terms of labor movement and restructuring of firms. It leads to the closure of certain positions and opening of new, sometimes higher positions, and labor mobility enables employees to change several organizations, which is often an important factor in the successful career development of personnel. No less important is the role of the leadership approach to human resources development and management. This approach becomes a vital competitive advantage and is sought- 


\section{Articles}

after by business and public organizations, by schools and university management, by all sorts of management hierarchies in our country and elsewhere in the world, especially in times of crisis. Only by building a successful leader, an industrial company will be able to cope with the modern challenges and achieve a complete and complex development of human resources in line with the company strategy.

\section{References}

Claessens, S., Tong, H. and Wei, S. (2011). From the Financial Crisis to Real Economy: Using Firm-Level Data to Identify Transmission Channels, Working paper 17360, NBER Working Paper Series Carnegie, D. (2018). Become an Effective Leader, Manjul Publishing House

Carnegie, D. (1995). Leader in You, Pocketbooks

Drucker, P. (2009) Effective Leader, Harper Collins

Drucker, P. (2005). Managing Challenges in XXI Century, Harper Collins

Drucker, P. (2003). Effective Manager, Harper Collins
Contemporary Challenges to Personnel Development

in the Industrial Company

Herzberg, F. (1968). One more time: How do you motivate employees? Harvard Business Review, 52-62

Iliev, Y. (2016). Systems for Management, UNSS, Publishing complex (in Bulgarian)

Iliev, Y. (2005). Human Resource Management, "Abagar" (in Bulgarian)

Iliev, Y. (2000). Leadership and Leaders in Business Organizations, "Abagar" (in Bulgarian)

Locke, E., (1968). Toward a theory of task motives and incentives. Organizational Behavior and Human Performance, 3, 157189

Mejia, L., Blankin, D., Cardy, R. (2011). Managing Human Resources, $1^{\text {st }}$ Edition, Pearson

Sharma, R. (2015). The Monk Who Sold His Ferrari, Harper Thorsons; Thorsons Classics Edition

Sharma, R. (2013). Leadership Lessons, Management Research, and Practice

Tridico, P. (2012). Financial Crisis and Global Imbalances: Its labor market Origins and the Aftermath, Cambridge Journal of Economics, vol. 36, 17-42 p. 